\title{
Quebec platelet disorder
}

INSERM

\section{Source}

INSERM. (1999). Orphanet: an online rare disease and orphan drug data base. Quebec platelet disorder. ORPHA:220436

Quebec platelet syndrome (QPS) is a platelet granule disorder characterized by moderate to severe bleeding after trauma, surgery or obstetric interventions, frequent ecchymoses, mucocutaneous bleeding and muscle and joint bleeds. 